\title{
Article
}

\section{Experimental analysis of defrosting and heating performance of a solar-assisted heat pump integrated phase change energy storage}

Chen, Haifei, Li, Guiqiang, Wang, Yunjie, Zhang, Fuwei, Badiei, Ali, Lu, Tao, Yang, Jie, Jiang, Lvlin and Zhang, Yang

Available at http://clok.uclan.ac.uk/38818/

Chen, Haifei, Li, Guiqiang, Wang, Yunjie, Zhang, Fuwei, Badiei, Ali ORCID: 0000-0002-2103-2955, Lu, Tao, Yang, Jie, Jiang, Lvlin and Zhang, Yang (2020) Experimental analysis of defrosting and heating performance of a solarassisted heat pump integrated phase change energy storage. International Journal of Energy Research, 44 (3). pp. 2173-2182. ISSN 0363-907X

It is advisable to refer to the publisher's version if you intend to cite from the work. http://dx.doi.org/10.1002/er.5076

For more information about UCLan's research in this area go to http://www.uclan.ac.uk/researchgroups/ and search for <name of research Group>.

For information about Research generally at UCLan please go to http://www.uclan.ac.uk/research/

All outputs in CLoK are protected by Intellectual Property Rights law, including Copyright law. Copyright, IPR and Moral Rights for the works on this site are retained by the individual authors and/or other copyright owners. Terms and conditions for use of this material are defined in the policies page. 


\section{Experimental analysis of defrosting and heating performance of a}

2 solar-assisted heat pump integrated phase change energy storage

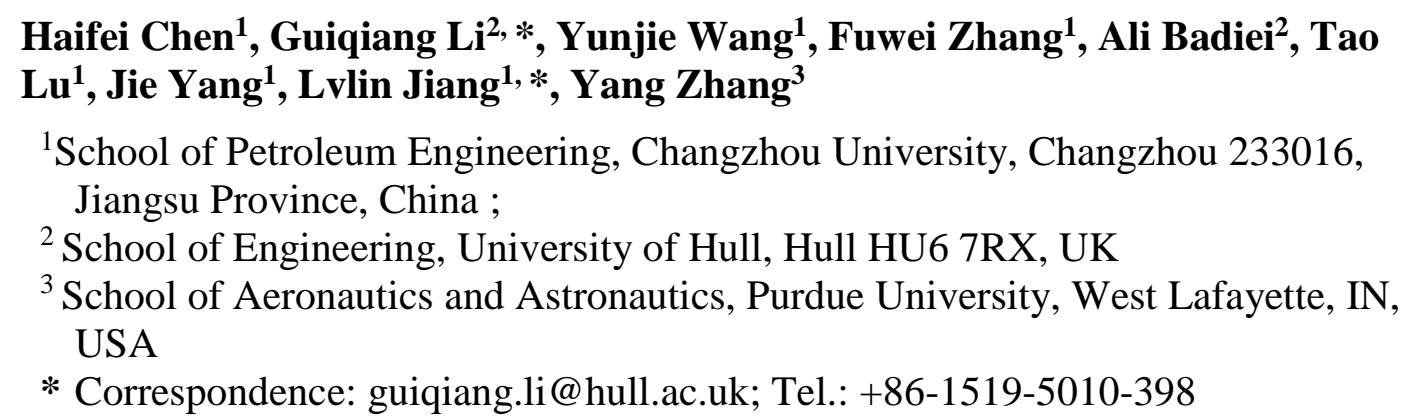

\section{Summary:}

This thesis investigates a novel solar-assisted heat pump integrated phase change energy storage system. The defrosting performance of this system was studied experimentally and the results were compared with two traditionally used methods: reverse cycle defrosting (RCD) method and hot gas bypass defrosting (HGBD) method. The results show that the phase change energy storage system has superior performance compared with traditional defrosting methods. The indoor temperature drop recorded was relatively small and the defrosting time was $75 \%$ of the reverse cycle defrosting system and $53 \%$ of HGBD system. The phase change energy storage system increased the condensation temperature which consequently increased the temperature difference of heat transfer resulting in higher conductivity in the defrosting progress. Compared with the method of RCD and the method of HGBD, the recovery time of the system was shortened by $90 \mathrm{~s}$ and $160 \mathrm{~s}$, respectively. The system works with low-temperature heat source and circulating water, which considerably reduces energy consumption, thereby improving the performance of the defrosting system. A further experimental study was also conducted on the heating performance and the results also indicated that the value of COP can reach up to 3.6 in daytime, and the indoor temperature can be stably maintained above $18{ }^{\circ} \mathrm{C}$ throughout the day.

KEYWORDS: Solar energy, Heat pump, Energy storage, Defrosting performance, Phase change

\section{INTRODUCTION}

With the excessive consumption of traditional energy sources, humans beings have to utilize new energy sources such as solar energy to reduce energy consumption and improve the efficiency ${ }^{1-3}$. More and more nationals and governments are considering the energy saving and environmental benefits of heat pumps. Market data shows that there is a sharp increase in the implementation and development of new heat pump technologies with higher COPs. At present, there is great interest in using heat pumps to save energy and using fuel and energy sources effectively ${ }^{4-6}$.

Currently, there are three main types of heat pumps namely water source heat pumps, ground source heat pumps and air source heat pumps. A ground water-source heat pump system with air pre-conditioning (GWHP-FAP) was proposed from the perspective of cascade utilization of low-level energy stored in the groundwater ${ }^{7}$. A 
new multifunctional water source heat pump system was also presented ${ }^{8}$. Pirjo Majuri studied ground source heat pumps and environmental policies ${ }^{9}$. A lot of researches have been carried out on air source heat pumps ${ }^{10-12}$. An air source heat pump with $\mathrm{R} 407 \mathrm{c}$ coolant investigated on the heating performance was proposed. Compared with traditional air source heat pumps, this new heat pump was suitable for market needs ${ }^{13}$.

The most ideal auxiliary heat source for solar heat pump heating system is air source heat pump because of its high efficiency and energy saving capacities, convenient use and wide application range. However, the frosting problem of air source heat pump seriously affects the operation of heat pump unit in winter and reduces the stability of system. RCD technique has become the most common method to solve the problem of undesired frost formation.

A defrosting method for cascade air source heat pumps (CASHPs) reverse circulation based on heat storage was proposed. Compared with the standard HGBD method, the defrosting time was greatly reduced and the defrosting energy consumption is reduced by more than two-thirds ${ }^{14}$. The defrosting heat and energy consumption of the experimental device in the process of reversible cycle defrosting was also studied. The indoor air supply is $71.8 \%$ of the total defrosting heat, of which $59.4 \%$ is used for defrosting. The maximum defrosting efficiency can reach up to $60.1 \%{ }^{15}$. Based on thermal energy storage (TES), a new reverse cycle defrosting method has been studied, which could improve indoor thermal comfort compared with traditional reverse cycle defrosting ${ }^{16}$. Wenju et al. developed a new anti-circulation hot gas defrosting method. The thawing time was shortened by $3 \mathrm{~min}$ or $38 \%$ by applying this method for the experimental (ASHP) device ${ }^{17}$. Defrosting in the ASHP unit could degrade performance by using more energy. The installation form of the outdoor coil affects the defrosting performance. Therefore, a study of performance during reverse cycle defrosting of an ASHP unit with a horizontal three-circuit outdoor coil was carried out 18. A previous study showed that the melted frost over outdoor coil could affect the defrosting performance during reverse cycle defrosting ${ }^{19}$. The proposed reverse cycle defrosting (NRCD) method was tested on a $8.9 \mathrm{~kW}$ ASHP device, where the discharge pressure increased by $0.33 \mathrm{MPa}$. Compared with the traditional RCD methods, the recovery time disappeared, and the total energy consumption decreased by $27.9 \%{ }^{20}$.

Due to air tightness of the indoor fan and poor energy storage capacities, the defrosting performance of the ordinary defrosting method (reverse circulation defrosting) is poor. Therefore, an ASHP defrost system was proposed in which the heat storage of the compressor casing is combined with reverse cycle defrosting (RCD) and hot gas bypass defrosting (HGBD) system using compressor shell to store heat ${ }^{21}$. A similar defrosting system was also designed, which combines the heat storage of the compressor shell with the hot gas bypass cycle ${ }^{22}$. Among the defrosting method with defrosting efficiency of $34.8 \%$, HGBD method proves to be more suitable. The applicability of HGBD method for $\mathrm{CO}_{2}$ heat pump was validated by experiments ${ }^{23}$. Then a defrosting cycle combined dual hot gas bypass defrosting (DHBD) and the accumulator heating method was developed ${ }^{24}$. Compared with HGBD method, DHBD method reduced the defrosting time by $36 \% 25$.

Phase change energy storage defrosting has also been widely studied. In recent 
years, performance improvement and energy demand reduction in refrigeration systems using phase change material (PCM) has attracted more attention ${ }^{26}$. A reverse cycle defrosting (NRCD) method has been proposed, which can improve the suction, temperature, defrosting and thermal recovery time of the system effectively during defrosting ${ }^{27}$. In order to solve the cold storage problem of cascade air source heat pump (CASHPs), a reverse cycle defrosting method based on thermal energy storage (TES) was developed ${ }^{28}$.

In this paper, based on the concept of energy space-time utilization, a new defrosting method for phase-change energy storage defrosting is presented. In order to verify the superiority of this defrosting method, an experimental system was designed to analyze the defrosting performance with RCD and HGBD methods. It was found that the performance of energy storage defrosting is obviously better than the other two defrosting modes, which can solve the frosting problem of ASHP effectively, thereby achieving the purpose of improving the operational stability of the energy storage solar ASHP heating system. Moreover, the performances of the heating system over the day were experimentally investigated. The experimental results show that the COP is always at a high level in the daytime, which greatly improves the economy and energy saving of the system. Finally, the influence of the outdoor temperature on the exergy efficiency was discussed.

\section{ANALYSIS OF DEFROSTING PROCESS}

\subsection{The process of defrosting}

Taking HGBD as an example, one feature of the defrosting process is to turn off the indoor heat exchanger fan during the entire heat exchange process to ensure that the indoor heat exchanger and the surrounding environment are always in the state of natural convection, so that the indoor ambient temperature changes as little as possible. Outdoor heat exchanger defrosting is a complex process with phase change, and the defrosting process usually consists of three stages.

In the first stage, fan stops to allow the condenser temperature to rise as quickly as possible for defrosting. In the second stage, the frost layer gradually melts and the fan continues to stop until the frost layer melts. In the third stage, the fan is turned on, so that all the frost that has melted into water is drained and evaporated.

\subsection{The mode of defrosting process}

The second stage in defrosting of ASHP system is the most important stage of the defrosting process when the ASHP operates, which is the phase change heat transfer process, including the heating of the frost layer and the melting of the frost layer. As the temperature increases in the wall of heat exchanger, the frost layer near the wall begins to melt first. Due to the pores in the frost, the melted water is absorbed by the unmelted frost layer, and when the unmelted frost layer is full of water, free flowing water begins to appear. At the same time, as the frost layer melts, the thickness of the frost layer changes continuously. If the influence of the external low temperature environment is considered, the surface of the frost layer that is in direct contact with 
the external low temperature environment will melt after the frost layer melts. In case of icing, it generates a gap between the hot wall and the frost layer.

\section{EXPERIMENTAL SYSTEM DESIGN}

\subsection{The design of experimental system}

The ASHP defrosting system used in the experiment mainly consists of a compressor, an energy storage device, an air source tube-fin and a plate heat exchanger, an electronic expansion valve, a four-way reversing valve, and an electromagnetic valve. Fig. 1 shows the schematic diagram of the system, which has a heating power of $2.5 \mathrm{~kW}$ and a rotor compressor with a rated power of $685 \mathrm{~W}$. The $47^{\circ} \mathrm{C}$ phase change material produced by Changzhou Haika Solar Heat Pump Co., Ltd. was used in the energy storage device. The data recorded in the experiment included: defrosting time, indoor temperature, end water supply temperature, compressor suction and discharge pressure, recovery heating time, defrosting energy consumption, and surface temperature of air source tube-fin heat exchanger fins at the end of defrosting. The precision degrees of solar irradiance, the turbine flowmeter and the temperature are $5 \%, 0.35 \%$ and $0.1^{\circ} \mathrm{C}$, respectively. In order to achieve the performance comparison of three different defrosting modes, the electromagnetic valve is controlled to turn on and off by manually switching the power source to distinguish switching of different defrosting modes.

FIGURE 1 Schematic diagram of the defrosting system

\subsection{Principle of RCD}

The RCD method is a relatively traditional defrosting method. When the condensation occurs on the heat exchanger and seriously affects the normal operation of the ASHP, the four-way reversing valve is turned by utilizing the two-way cooling and heating characteristics of the heat pump. The defrosting system will switch from heating to cooling mode, and the absorbed indoor heat energy will be discharged to the outdoor heat exchanger, thereby melting the outdoor heat exchanger frost.

When the RCD mode is running, the electromagnetic valves 1, 2, 3 and 7 are closed, and the electromagnetic valves 4, 5, 6, 8 and 9 are opened. The four-way reversing valve switches the heat pump unit from the heating cycle to the refrigerating cycle. At this time, the fan is turned off, and the refrigerant evaporates into the gas through the heat absorbed by the plate heat exchanger 1 and goes through the four-way reversing valve $(\mathrm{II} \rightarrow \mathrm{III})$. When the compressor is adiabatically compressed, the refrigerant (in gas form) enters the air source tube-fin heat exchanger through the fourway reversing valve $(I \rightarrow I V)$ and the electromagnetic valve 6 for defrosting. The refrigerant is then condensed into a liquid, which enters the electron through the electromagnetic valve 8 . After the electronic expansion valve 1 is throttled, the liquid enters the plate heat exchanger 1 to complete a defrosting cycle.

\subsection{Principle of HGBD}


The HGBD method achieves the purpose of defrosting mainly by directly introducing the high-temperature exhaust gas generated by the compressor into the indoor and outdoor heat exchangers via the bypass circuit. The heat of the exhaust gas causes the condensation outside the heat exchanger to fall off. During the operation of the defrosting system, the indoor and outdoor heat exchangers stop rotating, and the main source of heat energy for the defrosting comes from compression cycle. And it can melt the frost from the inside out.

When the HGBD mode is running, only electromagnetic valves 1 and 7 are opened, the remaining electromagnetic valves are closed, and the four-way reversing valve is not operating when the fan is turned off. The refrigerant compressed by the compressor defrosts and passes from the electromagnetic valve 1 to the air source tube-fin heat exchanger, and the defrosted refrigerant is throttled by the electronic expansion valve 2. The electromagnetic valve 7 and the four-way reversing valve (IV $\rightarrow$ III) are sucked by the compressor to complete a defrosting cycle.

\subsection{Principle of the energy storage defrosting}

The energy storage defrosting method is to connect the storage tank with the appropriate melting temperature to the ASHP unit, and uses the characteristics of the heat storage device to compensate the heat loss incurred in the defrosting process. When the ASHP is in the heating state, the unit will continue to provide heat to the air conditioning system, and will also provide heat to the heat storage device. When the ASHP is switched to the defrosting mode, the heat storage device will be turned on in a short time. The system quickly releases heat to the room, while also providing sufficient heat to the defrosting system to melt the frost on the outdoor heat exchanger.

When the phase change energy storage defrosting mode is running, the electromagnetic valves 1, 4, 5, 7 are closed, electromagnetic valves 2, 3, 6, 8, 9 are opened, and the four-way reversing valve is operating. At this time, the fan turns off and energy storage takes place and the device acts as an evaporator for the system. The refrigerant absorbs heat through the plate heat exchanger 2 and enters the compressor (II $\rightarrow$ III) for adiabatic compression. The compressed high-temperature and highpressure refrigerant goes through the four-way reversing valve $(\mathrm{I} \rightarrow \mathrm{IV})$ and the electromagnetic valve 6 to enter the air source tube-fin heat exchanger for defrosting, then throttles by the electronic expansion valve 1 and returns to the heat exchanger 2 to complete the defrosting cycle.

\section{EXPERIMENTAL ANALYSIS}

In the Shijiazhuang area, two houses were built with foam color steel plates for experimental research. The indoor air temperature and humidity were adjusted to 
simulate outdoor weather conditions under ASHP frosting conditions by installing a refrigeration unit, an air heater, a humidifier, and a dehumidifier.

At present, it is found that the ASHP is most likely to be frosted when operating under meteorological conditions with a relative humidity of more than $65 \%$ between $12.8^{\circ} \mathrm{C}$ and $5.8^{\circ} \mathrm{C}$. When the relative humidity is constant, the defrosting energy consumption and defrosting time will increase first and then decrease with the decrease of air temperature. The $-3^{\circ} \mathrm{C}$ working condition was used as the most unfavorable condition for designing ASHP defrosting. And the relative humidity was $65 \%$. The thickness of the frost layer at the beginning of the defrosting is not uniform, and the average thickness is about $3 \mathrm{~mm}$. The solar module and the air source module are directly connected in parallel. When the outlet temperature of the solar collector is greater than the outdoor ambient temperature, the system starts the solar heat pump mode, otherwise the air source heat pump is activated.

\subsection{Analysis of the temperature characteristic of the system}

The ASHP is used as an auxiliary heat source in the energy storage type solar assisted ASHP heating system, and its function is to provide heat to the interior of the building in colder weather conditions to meet the occupants' thermal comfort requirements. However, the ASHP frosting and defrosting process will bring about a series of problems such as increase in the heat supply and the large fluctuation of the indoor environment temperature. Therefore, when evaluating the performance of different defrosting modes, the first problem to be considered is the change in room temperature during the defrosting of the ASHP. The temperature measurement points are arranged in four directions from east to west, north and south, and finally an indoor average temperature is obtained. Fig. 2 and Fig. 3 show the changes in the indoor water supply temperature and the indoor temperature air in different defrosting modes.

FIGURE 2 Variation curve of indoor water supply temperature during defrosting

FIGURE 3 Variation curve of indoor air temperature during defrosting

As shown in Fig.2 and Fig.3, among the three defrosting modes the defrosting time of the HGBD is longer than that of the other two defrosting methods, and the whole defrosting process takes about 510s. Compared with the other two defrosting modes, the power consumption required for hot gas bypass defrosting is from input power of the compressor, so the defrosting process takes a longer time to complete.

Moreover, the indoor water and air temperature drops of energy storage defrosting is the smallest, and the reverse circulation defrosting is the largest. This is because HGBD directly circulates the exhaust gas of the compressor to the air source tube-fin 
heat exchanger for defrosting. While energy storage defrosting is performed by the system to absorb heat from energy storage device, the compressor provides the system with required energy for defrosting. Hence, both compressor and energy storage device do not need to circulate water from the room and the indoor environment. The heat is absorbed, so the water supply temperature and the indoor temperature decrease rate are low during this time. However, since the time required for the hot gas bypass defrosting is about 1.9 times that of the energy storage defrosting, the indoor air temperature is still reduced by $8^{\circ} \mathrm{C}$. The indoor water supply temperature drops sharply from $45^{\circ} \mathrm{C}$ to about $5^{\circ} \mathrm{C}$ during the reverse cycle defrosting process. This is due to the operation of four-way reversing valve which causes the system to switch from the heating to the cooling mode for the purpose of defrosting. Then the indoor circulating water has absorbed a large amount of heat as the low-temperature heat source of the system, so the water supply temperature was drastically lowered. Meanwhile, with the decrease of indoor circulating water temperature, the indoor ambient air temperature drops due to convective heat exchange with the circulating water, which severely influences the thermal comfort of occupants.

It can be seen from the above analysis that the energy storage defrosting is obviously superior to the two common defrosting methods of RCD and HGBD. The defrosting time is only $75 \%$ of the RCD, and $53 \%$ of the HGBD. When defrosting, the indoor temperature drop is small, which can better meet the occupants' thermal comfort requirements.

\subsection{Analysis of system pressure characteristics}

As shown in Fig. 4, when the reverse cycle defrosting is started, there will be a short rise in the suction pressure of the compressor. This is because the plate heat exchanger 1 operates as the system operation mode is switched. The evaporator is connected to the suction port of the compressor. At this time, since the refrigerant does not undergo electronic expansion, the gas-liquid two-phase refrigerant in the exchanger 1 enters the suction port of the compressor through the suction line. The throttle valve is also in a high pressure state, which will increase the suction pressure of the compressor. However, this high-pressure refrigerant is quickly absorbed, and as the evaporator the exchanger 1 cannot satisfy the evaporation demand of the liquid refrigerant by the indoor circulating water and the heat absorbed in the indoor environment. This causes insufficient evaporation of the refrigerant and the evaporation pressure drops rapidly. The suction pressure of the compressor also drops rapidly. The minimum suction pressure occurs at $60 \mathrm{~s}$ after the start of the defrosting, and the magnitude is about $0.2 \mathrm{Mpa}$. For HGBD, the trend of change in the suction pressure of the compressor during operation is similar to that of the RCD. However, Fig.4 shows that the variation of the suction pressure in the compressor during operation is smaller 
than the variation of the suction pressure in the compressor during the RCD, and there is no sudden increase or decrease of the suction pressure. The mechanical impact of the unit is also relatively small, which can effectively extend the service life of the heat pump. It can be observed that the average values of the inspiratory pressure during RCD, HGBD and energy storage defrosting are $0.234 \mathrm{Mpa}, 0.238 \mathrm{Mpa}$ and $0.336 \mathrm{Mpa}$, respectively. The average value of suction pressure during the HGBD process is much smaller than that of the energy storage defrosting. This is because when the energy storage defrosting is performed, the energy storage device serves as a low-temperature heat source, and the exchanger 2 provides sufficient heat for the evaporation of the refrigerant, thereby increasing evaporation rate of the refrigerant. The suction pressure of the compressor is greatly improved, preventing the system from shutting down, and ensuring the reliability and stability of the system in the defrosting process.

FIGURE 4 Variation curve of the compressor suction pressure

As shown in Fig. 5, variation trends of the exhaust pressures of RCD and HGBD modes are very similar, and demonstrating a trend of decrease first and then increase, but there is a difference in the magnitude of the change. This happens because regardless of the defrosting mode of the system, the exhaust port of the compressor is always connected to the air source tube-fin heat exchanger. At this time, the air source tube-fin heat exchanger is taken as the condenser of the system, and the internal condensation temperature is relatively low. The discharge pressure of the compressor is directly related to the condensation temperature, and then the discharge pressure of the compressor will initially show a subtle decline. Then, as time goes on, the frosting layer on the air source tube-fin heat exchanger melts continuously, the condensation temperature begins to rise, and the exhaust pressure also tends to rise continuously.

Compared with the RCD and HGBD, the displacement pressure of the compressor during storage defrosting is larger. The average exhaust pressure during the defrosting process is $32 \%$ and $12 \%$ higher than that of the RCD and the HGBD, respectively. On the one hand, the reliability of the system operation is ensured, and the phenomenon of "oil spill" is prevented. On the other hand, the condensation temperature is also increased, hence the increase of heat transfer temperature difference is more conductive to defrosting of the system.

FIGURE 5 Variation curve of the compressor discharge pressure

\subsection{Analysis of system recovery heating capacity}

As shown in Fig.3, the longer the delay in system heat up, the greater the impact on indoor environment. The main purpose of defrosting by ASHP is to better meet 
occupants' requirements for thermal comfort. Therefore, in studying the defrosting performance of the ASHP, it is also necessary to consider its heat-recovery capability. In addition to the surface temperature of the heat exchanger, the thickness of the frost, and the pressure difference between the inlet and the outlet of the heat exchanger, the change in the outlet temperature of the working fluid in the heat exchanger is used as a termination condition.

Table 1 Three defrosting methods to restore heating parameters

It can be seen from Table 1 that the time taken to restore heat during RCD is the longest. This is because the evaporator plate heat exchanger 1 in the defrosting absorbs a large amount of heat from the indoor circulating water and indoor environment. As a result, the temperature of both indoor circulating water and indoor environment drops significantly. For HGBD, the defrosting energy is provided by the compressor with less influence on indoor circulating water and indoor temperature, so the time for restoring heating is shorter than that of RCD. Due to the stable low-temperature heat source during energy storage defrosting, defrosting time is shorter, and the decrease in temperature of circulating water in the plate heat exchanger 1 is less when compared with the two defrosting modes. Therefore, the time required to restore heating is the shortest. The heat recovery time has shortened by 90 s and 160 s respectively compared to the RCD and the HGBD methods. The ability to restore heat is the strongest in energy storage defrosting. At the same time, it can be seen that when the system is running in energy storage defrosting mode, the temperature of the surface of air source tube-fin heat exchanger is the highest after defrosting is finished $\left(6{ }^{\circ} \mathrm{C}\right.$ higher than the other two defrosting modes). Besides, the problem of multiple defrosts caused by defrosting water on the surface of the air source tube-fin heat exchanger can be completely solved.

\subsection{Analysis of system defrosting energy}

Table 2 Comparison of defrosting energy consumption and compressor input power of three defrosting modes

It can be seen from Table 2 that despite the shorter defrost time of the reverse cycle compared to the HGBD, the energy consumed by the two is similar. This can be explained by the energy consumed during the heat recovery period. Since the RCD takes a long time to restore heat after the defrosting, the total energy consumed by the two methods end up being similar. At the same time, the average input power of the compressor during storage defrosting is higher than the other two defrosting modes. This is because the energy storage material passes through the plate heat exchanger 2 
when the system performs energy storage defrosting. The evaporation of the refrigerant provides sufficient heat to accelerate the evaporation rate, thereby increasing its mass flow rate, the suction and discharge pressure and temperature of the compressor, and the input power of the compressor. However, due to its relatively short defrost and heat recovery time, it can save the energy effectively compared with the other two defrosting modes.

\section{EXPERIMENTAL STUDY ON HEATING SYSTEM}

\subsection{Analysis of the heating performance during daytime}

Based on the monitor of the measured outdoor weather changes in the heating season in Shijiazhuang, a typical meteorological day was selected to test the operating performance and heating efficiency of the system.

FIGURE 6 Indoor and outdoor temperature and cop change with solar radiation during the daytime

Performance tests were carried out on the operating conditions of the system. The experiments were recorded for 8 hours from 8:00 am to 16:00 pm. The variation of solar radiation intensity and outdoor temperature with time is shown in Fig.6.

The solar radiation increases toward mid-day and then decreases, the average solar radiation intensity being $752.7 \mathrm{~W} \cdot \mathrm{m}^{-2}$, and the peak appears at $\sim 12: 00$, at $950.2 \mathrm{~W} \cdot \mathrm{m}^{-2}$. Compared with the intensity of radiation intensity, maximum outdoor temperature occurs slightly later in day, at $13: 30$ and the value is $2.5^{\circ} \mathrm{C}$. And the outdoor temperature is between $-14^{\circ} \mathrm{C}$ and $2.5^{\circ} \mathrm{C}$. The average indoor temperature is $18^{\circ} \mathrm{C}$ within 8 hours from 8:00 am to $16: 00 \mathrm{pm}$. Finally, the indoor temperature is higher than $20^{\circ} \mathrm{C}$, which shows that the system adequately meets the needs of indoor heating needs.

Fig. 6 shows that the variation in the COP of the system is maintained between 3.6 and 5.3, with average value of 4.5. It can be concluded that the system can fully utilize the solar energy to meet building heating requirements, and phase change energy storage if needed.

\subsection{Analysis of the heating performance during night}

FIGURE 7 Outdoor temperature and exergy efficiency change with the time

Although the heat pump system performance can be analyzed using COP based on the first law of thermodynamics. However, it can only explain the quantitative relationship between energy transfer and transformation. Only the "quantity" of energy is considered, and the loss of energy and the direction of transmission cannot be evaluated. To examine the exergy efficiency, the second law analysis was implemented based on experimental tests. When the process involves a long time, and the temperature level of the system is quite different from the environment, ignoring the change of the environment temperature will cause a large error. Therefore, considering the dynamic changes of the outdoor temperature will have a more reasonable impact on 
the exergy efficiency in the whole process. As shown in Fig.7, exergy efficiency fluctuates greatly from morning to night due to the large change of outdoor temperature. When the outdoor temperature is $2.5^{\circ} \mathrm{C}$, the exergy efficiency reaches the lowest value of $8 \%$. The maximum exergy efficiency is $30 \%$, and average exergy efficiency is $21 \%$.

FIGURE 8 Temperature of phase change storage

Fig. 8 shows the variation of the phase change storage temperature. By daylight, the temperature of the phase change storage is relatively constant due to the presence of solar irradiation, and is maintained at about $47^{\circ} \mathrm{C}$. By night, the phase change latent heat of the phase change material has been completely released, and the energy storage condenser is heated by the sensible heat of phase change material. Therefore, the internal temperature of the energy storage condenser decreases in the meantime. The energy storage type solar ASHP system ensures the stability of the heat provision by the energy storage condenser. Solar energy's "shifting peaks and filling valleys" maximized the use of solar energy for heating, achieving a significant increase in system economy and energy efficiency.

\section{CONCLUSIONS}

This paper analyzes and compares the defrosting performance of three defrosting methods, namely: phase change energy storage defrosting method, RCD and HGBD. The analyzed parameters include: defrosting time, indoor temperature, terminal water supply temperature, compressor suction and discharge pressure, recovery heating time, defrosting energy consumption, and surface temperature of air source tube-fin heat exchanger. Following conclusions were drawn from the investigation of the three defrosting methods:

1. Phase change energy storage defrosting method was shown to be better than the two conventional defrosting methods: RCD and HGBD. The defrosting time was only $75 \%$ of the RCD and $53 \%$ of the HGBD. The recorded indoor temperature drop was also small during defrosting in the phase change energy storage method.

2. When the energy storage system is in defrosting mode, the compressor's exhaust pressure fluctuates, and the average exhaust pressure during the defrosting process is $23 \%$ and $21 \%$ higher than RCD and HGBD respectively. This superior performance not only ensures the reliability of the system operation, but also prevents the phenomenon of "running oil". It also increases the condensation temperature and makes the heat transfer temperature difference increase, resulting in higher conductivity.

3. Despite RCD and HGBD system, energy storage defrosting system has a stable low temperature heat source due to energy storage defrosting, the defrosting time is shorter, and the temperature of circulating water is lower. The time required to restore heating is the shortest in energy storage system (it is shortened by $90 \mathrm{~s}$ and $160 \mathrm{~s}$ respectively compared to RCD and HGBD), and the ability to restore heat is the 
strongest. Since the defrosting and heat recovery times are relatively short, compared with the other two defrosting modes, the energy storage defrosting system will effectively reduce energy consumption required for defrosting progress.

4. Experimental research on the heating performance of the system was studied out. The COP value of the system was maintained between 3.6 and 5.3. Although the outdoor temperature variation is huge, the fluctuation of the indoor temperature is small, and is always maintained above $18^{\circ} \mathrm{C}$, which ensures that the occupants' thermal comfort requirements are met stably and reliably.

\section{ACKNOWLEDGEMENTS}

This research is supported by the National Natural Science Foundation of China (No. 51906020) and the Natural Science Foundation of Jiangsu Educational committee (No. 18KJD480001).

\section{REFERENCES}

1. Chen, H.; Ji, J.; Pei, G.; Yang, J.; Zhang, Y., Experimental and numerical comparative investigation on a concentrating photovoltaic system. J Clean Prod 2018, 174, 1288-1298.

2. Li, G.; Zhao, X.; Ji, J., Conceptual development of a novel photovoltaic-thermoelectric system and preliminary economic analysis. Energy Convers. Manage. 2016, 126, 935-943.

3. Li, G.; Xuan, Q.; Lu, Y.; Pei, G.; Su, Y.; Ji, J., Numerical and lab experiment study of a novel concentrating PV with uniform flux distribution. Solar Energy Materials and Solar Cells 2018, 179, $1-9$.

4. Deng, J.; Wei, Q.; Liang, M.; He, S.; Zhang, H., Field test on energy performance of medium-depth geothermal heat pump systems (MD-GHPs). Energy and Buildings 2019, 184, 289-299.

5. Sichilalu, S.; Tazvinga, H.; Xia, X., Optimal control of a fuel cell/wind/PV/grid hybrid system with thermal heat pump load. Solar Energy 2016, 135, 59-69.

6. Vorushylo, I.; Keatley, P.; Shah, N.; Green, R.; Hewitt, N., How heat pumps and thermal energy storage can be used to manage wind power: A study of Ireland. Energy 2018, 157, 539-549.

7. Wang, Z.; Wang, L.; Ma, A.; Liang, K.; Song, Z.; Feng, L., Performance evaluation of ground watersource heat pump system with a fresh air pre-conditioner using ground water. Energy Convers. Manage. 2019, 188, 250-261.

8. Liu, X.; Hui, F.; Guo, Q.; Zhang, Y.; Sun, T., Experimental study of a new multifunctional water source heat pump system. Energy and Buildings 2016, 111, 408-423.

9. Majuri, P., Ground source heat pumps and environmental policy - The Finnish practitioner's point of view. J Clean Prod 2016, 139, 740-749.

10. Hu, B.; Wang, R. Z.; Xiao, B.; He, L.; Zhang, W.; Zhang, S., Performance evaluation of different heating terminals used in air source heat pump system. International Journal of Refrigeration 2019, 98, 274-282.

11. Huang, B.; Jian, Q.; Luo, L.; Zhao, J., Experimental study of enhancing heating performance of the air-source heat pump by using a novel heat recovery device designed for reusing the energy of the compressor shell. Energy Convers. Manage. 2017, 138, 38-44.

12. Su, W.; Li, W.; Zhang, X., Simulation analysis of a novel no-frost air-source heat pump with integrated liquid desiccant dehumidification and compression-assisted regeneration. Energy Convers. 
Manage. 2017, 148, 1157-1169.

13. Dong, X.; Tian, Q.; Li, Z., Experimental investigation on heating performance of solar integrated air source heat pump. Appl. Therm. Eng. 2017, 123, 1013-1020.

14. Qu, M.; Li, T.; Deng, S.; Fan, Y.; Li, Z., Improving defrosting performance of cascade air source heat pump using thermal energy storage based reverse cycle defrosting method. Appl. Therm. Eng. 2017, $121,728-736$.

15. Dong, J.; Deng, S.; Jiang, Y.; Xia, L.; Yao, Y., An experimental study on defrosting heat supplies and energy consumptions during a reverse cycle defrost operation for an air source heat pump. Appl. Therm. Eng. 2012, 37, 380-387.

16. Minglu, Q.; Liang, X.; Deng, S.; Yiqiang, J., Improved indoor thermal comfort during defrost with a novel reverse-cycle defrosting method for air source heat pumps. Build Environ 2010, 45, (11), 23542361.

17. Wenju, H.; Yiqiang, J.; Minglu, Q.; Long, N.; Yang, Y.; Shiming, D., An experimental study on the operating performance of a novel reverse-cycle hot gas defrosting method for air source heat pumps. Appl. Therm. Eng. 2011, 31, (2-3), 363-369.

18. Mengjie, S.; Xiangguo, X.; Shiming, D.; Ning, M., An Experimental Study on Performance During Reverse Cycle Defrosting of an Air Source Heat Pump with a Horizontal Three-circuit Outdoor Coil. Energy Procedia 2014, 61, 92-95.

19. Song, M.; Pan, D.; Li, N.; Deng, S., An experimental study on the negative effects of downwards flow of the melted frost over a multi-circuit outdoor coil in an air source heat pump during reverse cycle defrosting. Appl. Energy 2015, 138, 598-604.

20. Long, Z.; Jiankai, D.; Yiqiang, J.; Yang, Y., A novel defrosting method using heat energy dissipated by the compressor of an air source heat pump. Appl. Energy 2014, 133, 101-111.

21. Liu, Z.; Zhao, F.; Zhang, L.; Zhang, R.; Yuan, M.; Chi, Y., Performance of bypass cycle defrosting system using compressor casing thermal storage for air-cooled household refrigerators. Appl. Therm. Eng. 2018, 130, 1215-1223.

22. Liu, Z.; Fan, P.; Wang, Q.; Chi, Y.; Zhao, Z.; Chi, Y., Air source heat pump with water heater based on a bypass-cycle defrosting system using compressor casing thermal storage. Appl. Therm. Eng. 2018, 128, 1420-1429.

23. Hu, B.; Yang, D.; Cao, F.; Xing, Z.; Fei, J., Hot gas defrosting method for air-source transcritical CO 2 heat pump systems. Energy and Buildings 2015, 86, 864-872.

24. Kim, J.; Choi, H.-J.; Kim, K. C., A combined Dual Hot-Gas Bypass Defrosting method with accumulator heater for an air-to-air heat pump in cold region. Appl. Energy 2015, 147, 344-352.

25. Choi, H.-J.; Kim, B.-S.; Kang, D.; Kim, K. C., Defrosting method adopting dual hot gas bypass for an air-to-air heat pump. Appl. Energy 2011, 88, (12), 4544-4555.

26. Bista, S.; Hosseini, S. E.; Owens, E.; Phillips, G., Performance improvement and energy consumption reduction in refrigeration systems using phase change material (PCM). Appl. Therm. Eng. 2018, 142, 723-735.

27. Dong, J.; Li, S.; Yao, Y.; Jiang, Y.; Tian, Y.; Tian, H., Defrosting performances of a multi-split air source heat pump with phase change thermal storage. International Journal of Refrigeration 2015, $55,49-59$.

28. Qu, M.; Tang, Y.; Zhang, T.; Li, Z.; Chen, J., Experimental investigation on the multi-mode heat discharge process of a PCM heat exchanger during TES based reverse cycle defrosting using in cascade air source heat pumps. Appl. Therm. Eng. 2019, 151, 154-162. 
2 Figure Captions

3 1. FIGURE 1 Schematic diagram of the defrosting system

4 2. FIGURE 2 Variation curve of indoor water supply temperature during defrosting

5 3. FIGURE 3 Variation curve of indoor air temperature during defrosting

6 4. FIGURE 4 Variation curve of the compressor suction pressure

7 5. FIGURE 5 Variation curve of the compressor discharge pressure

8 6. FIGURE 6 Indoor and outdoor temperature and cop change with solar radiation during the daytime

7. FIGURE 7 Outdoor temperature and exergy efficiency change with the time

8. FIGURE 8 Variation of the temperatures with the inlet water temperature

\section{Table Captions}

1. Table 1 Three defrosting methods to restore heating parameters

2. Table 2 Comparison of defrosting energy consumption and compressor input power of the three defrosting modes

2

3

5

27




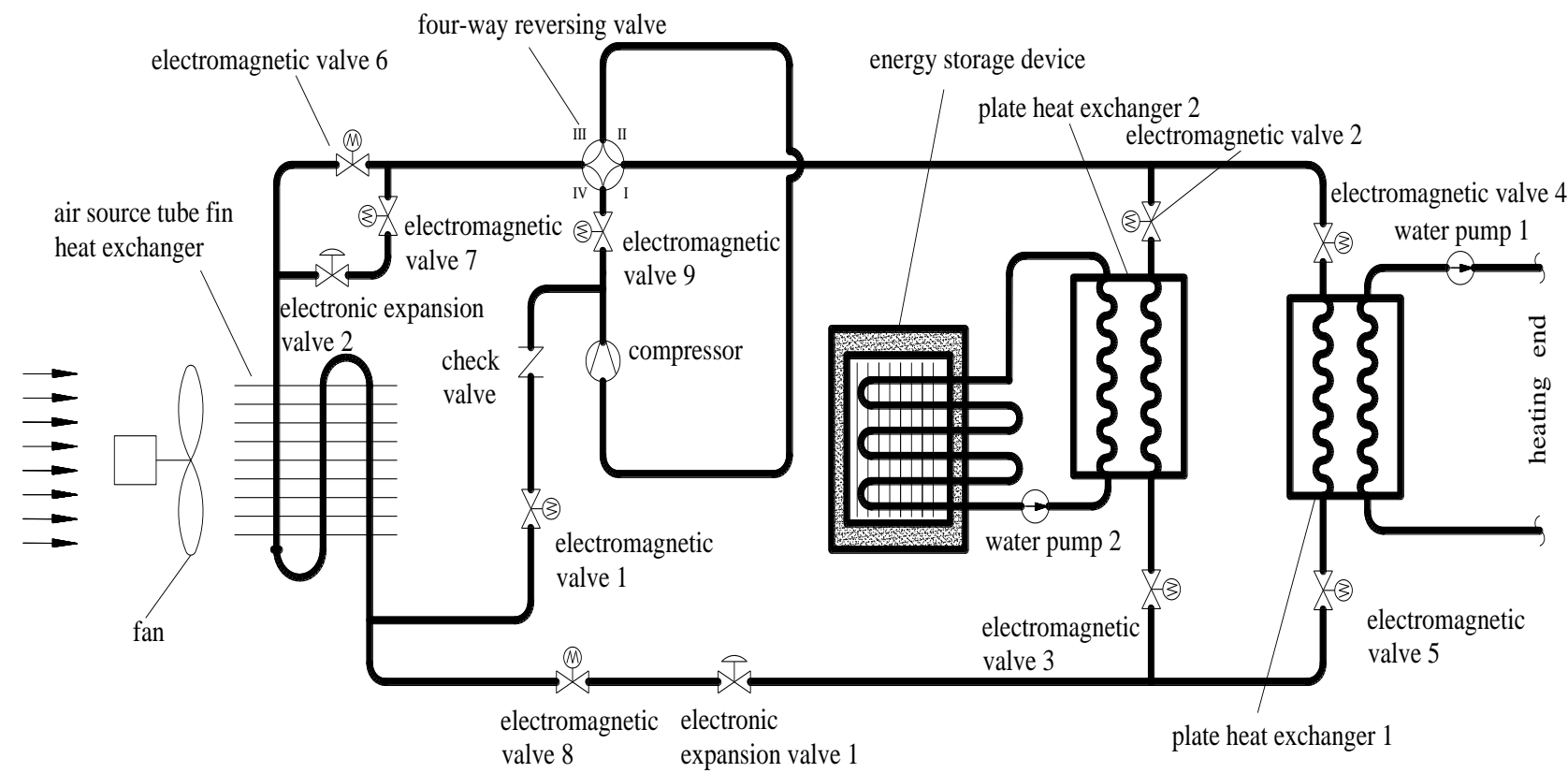

3

FIGURE 1 Schematic diagram of the defrosting system

4

5

6

8

9 


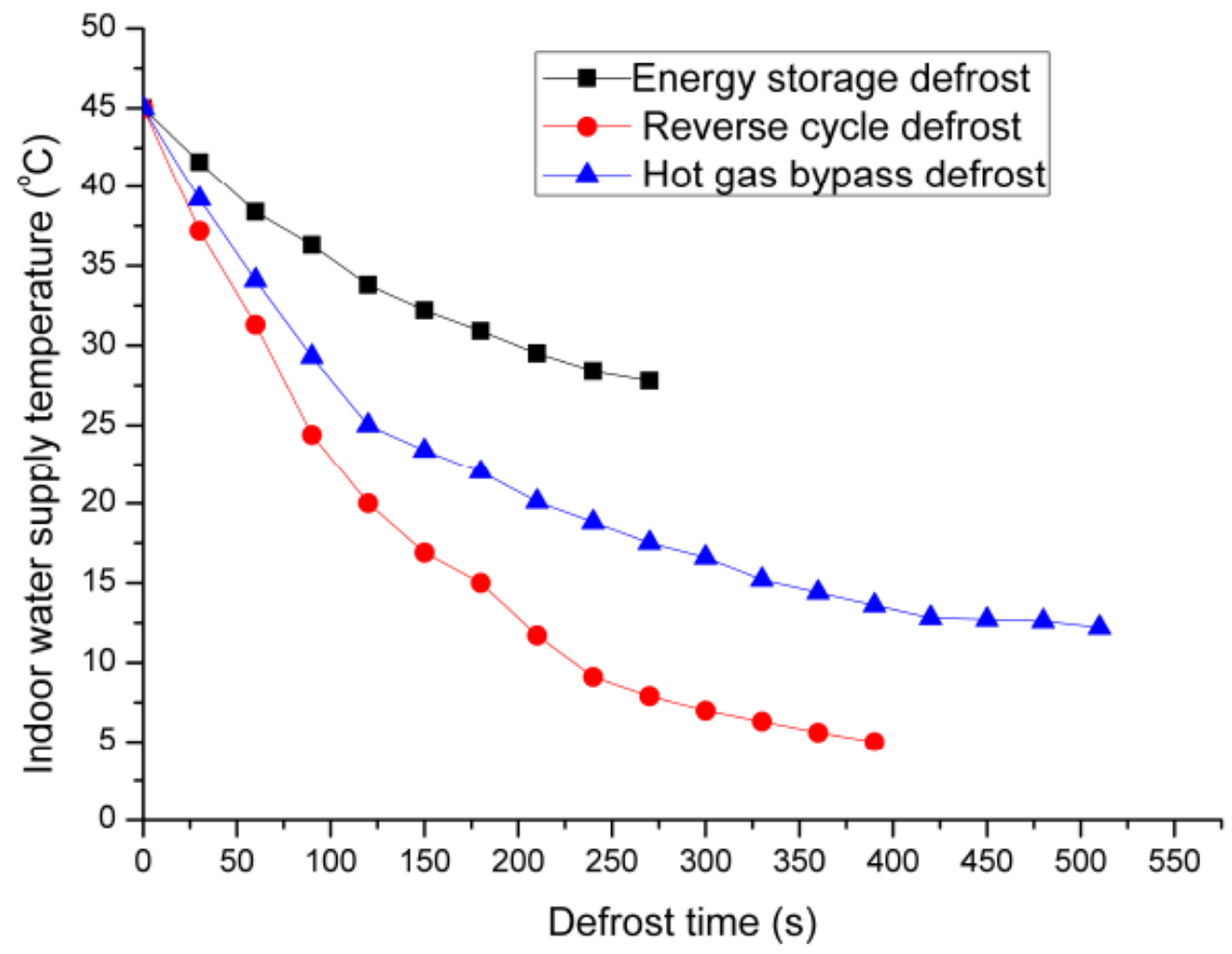

FIGURE 2 Variation curve of indoor water supply temperature during defrosting 4 


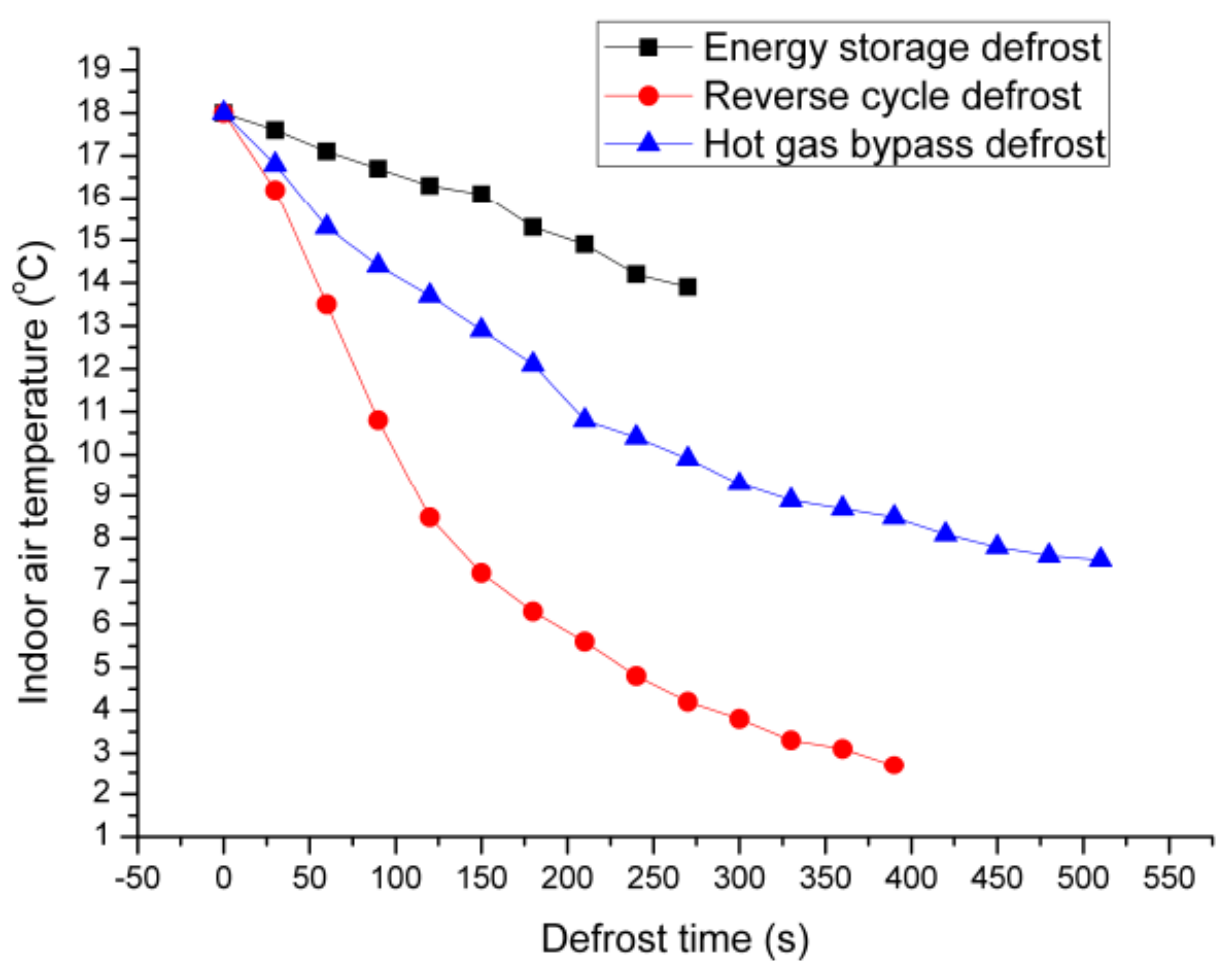
3 4 5 6 7 8 9 10 11 12 13 14 15 16 17 18 19 20 21 22 23 24 25 26

FIGURE 3 Variation curve of indoor air temperature during defrosting 


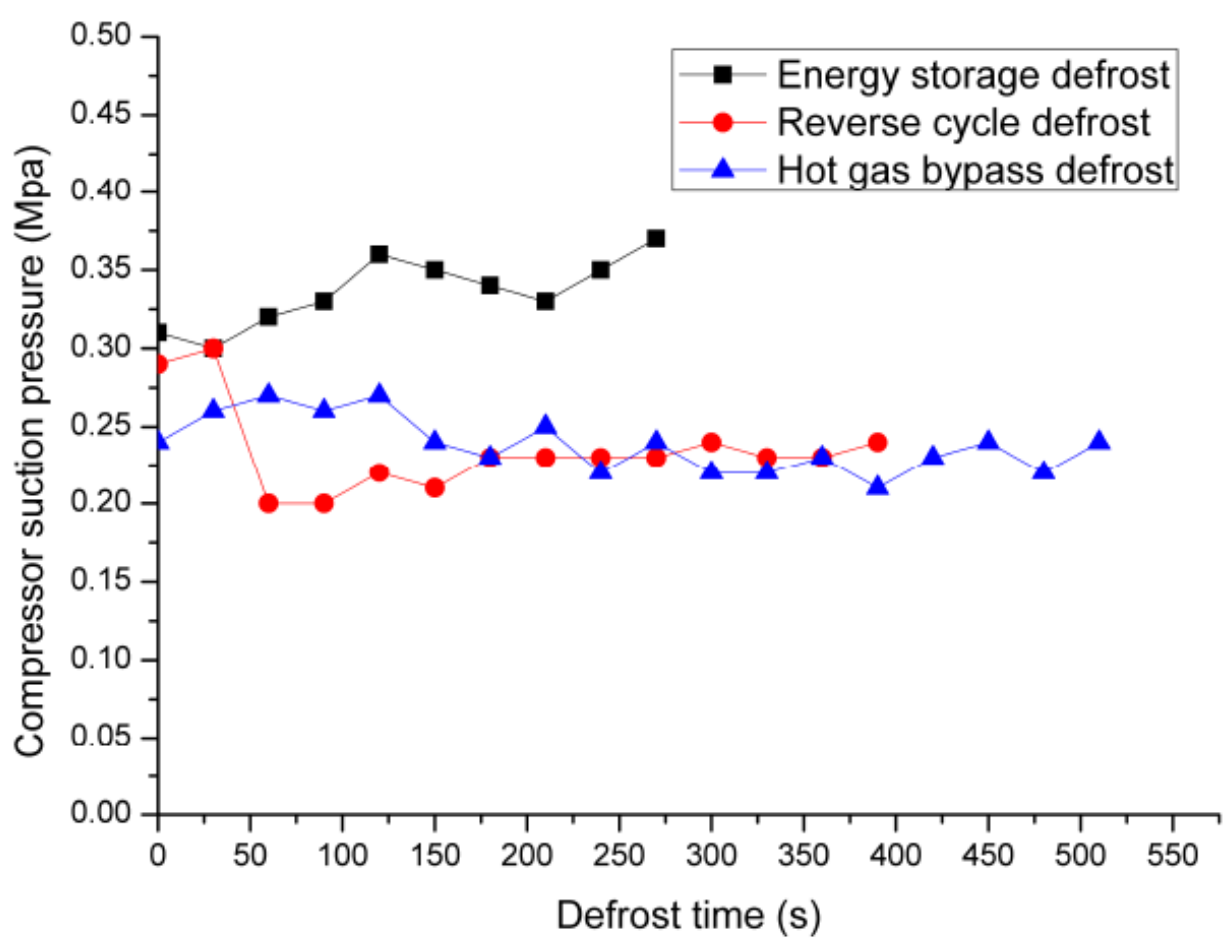

2

3

4

5

6

7

8

9

10

11

12

13

14

15

16

17

18

19

20

21

22

23

24

25

26

FIGURE 4 Variation curve of the compressor suction pressure 


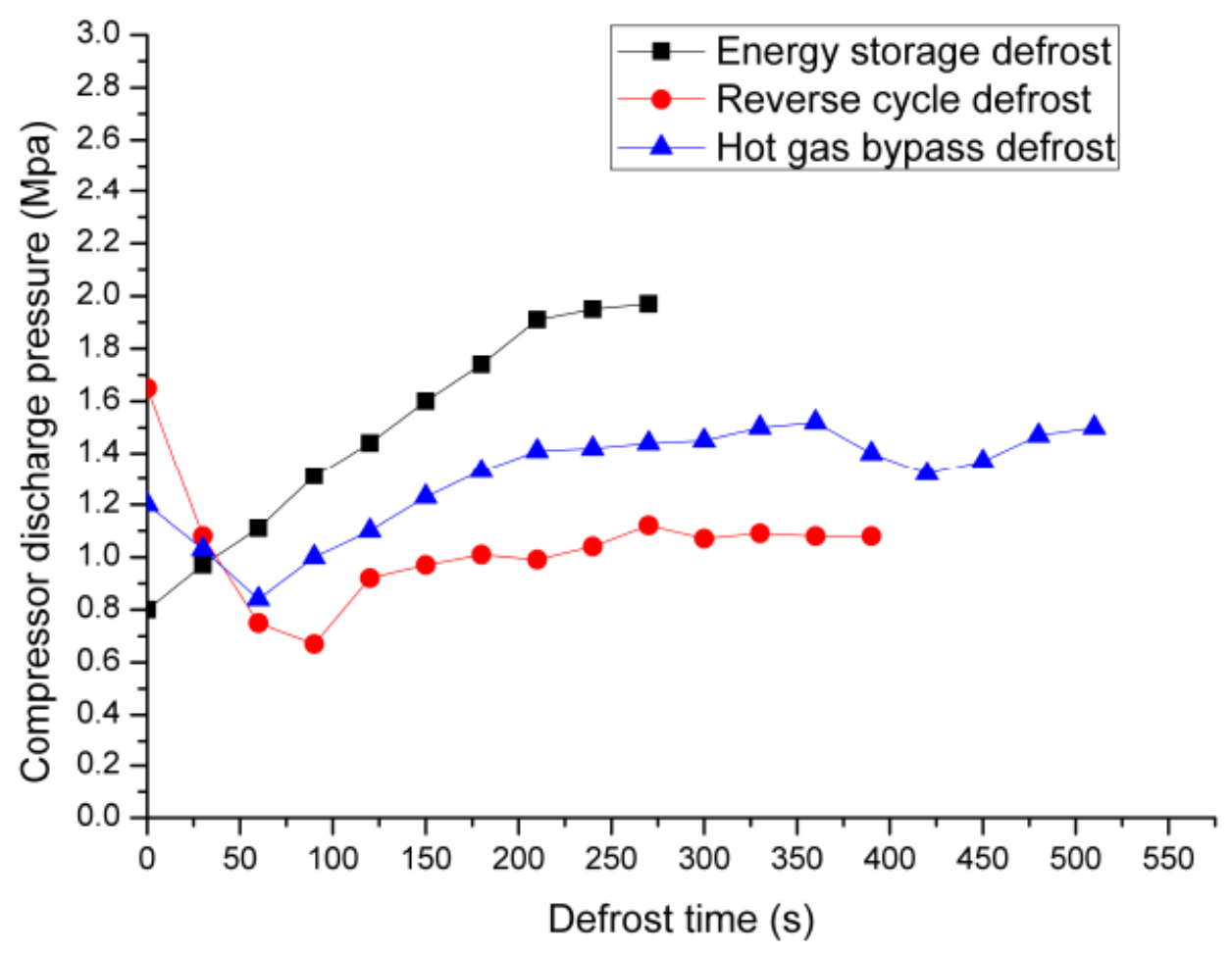

FIGURE 5 Variation curve of the compressor discharge pressure

3

4

5

6

7

8

9

10

11

12

13

14

15

16

17

18

19

20

21

22

23

24

25

26 


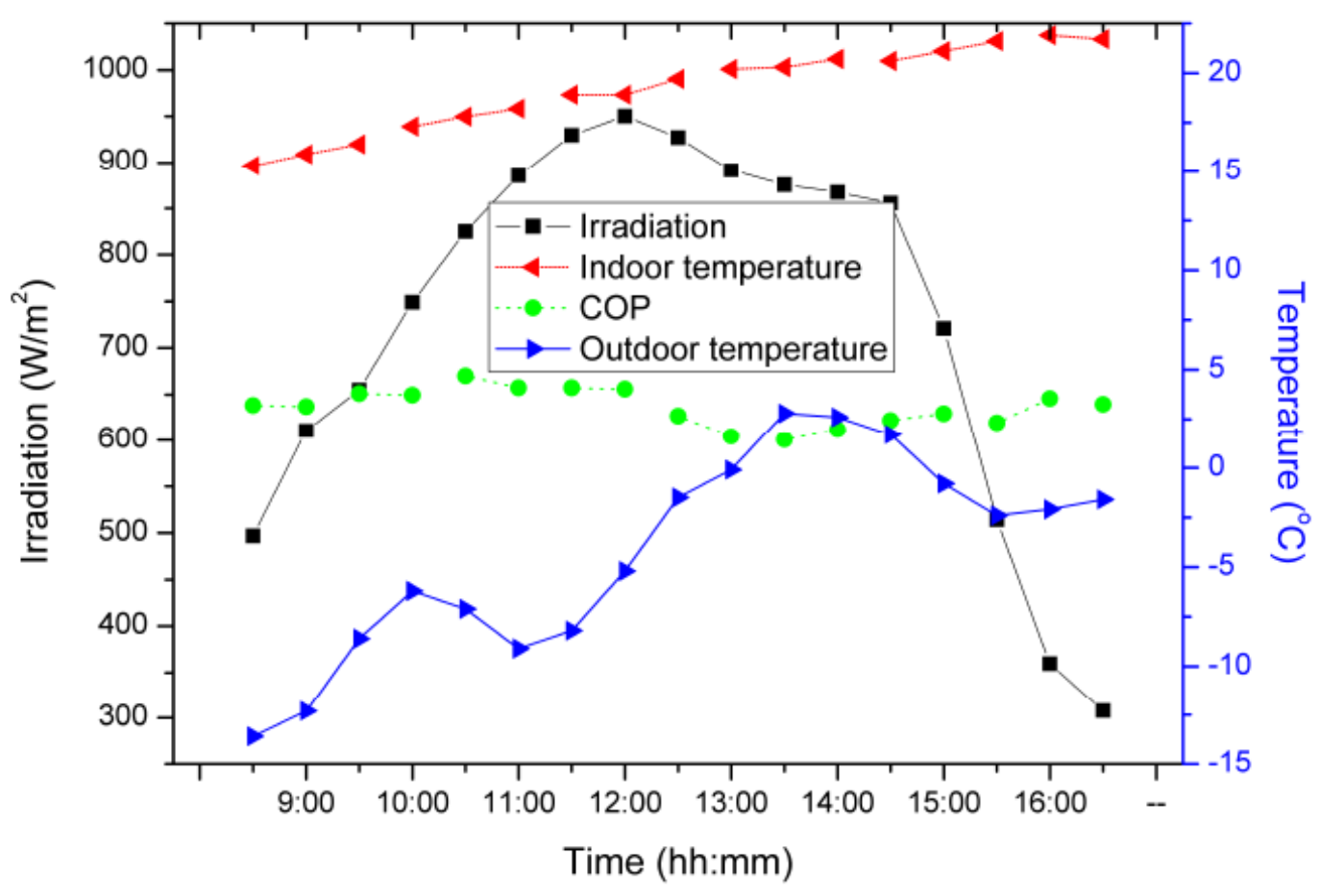

FIGURE 6 Indoor and outdoor temperature and cop change with solar radiation during the daytime 


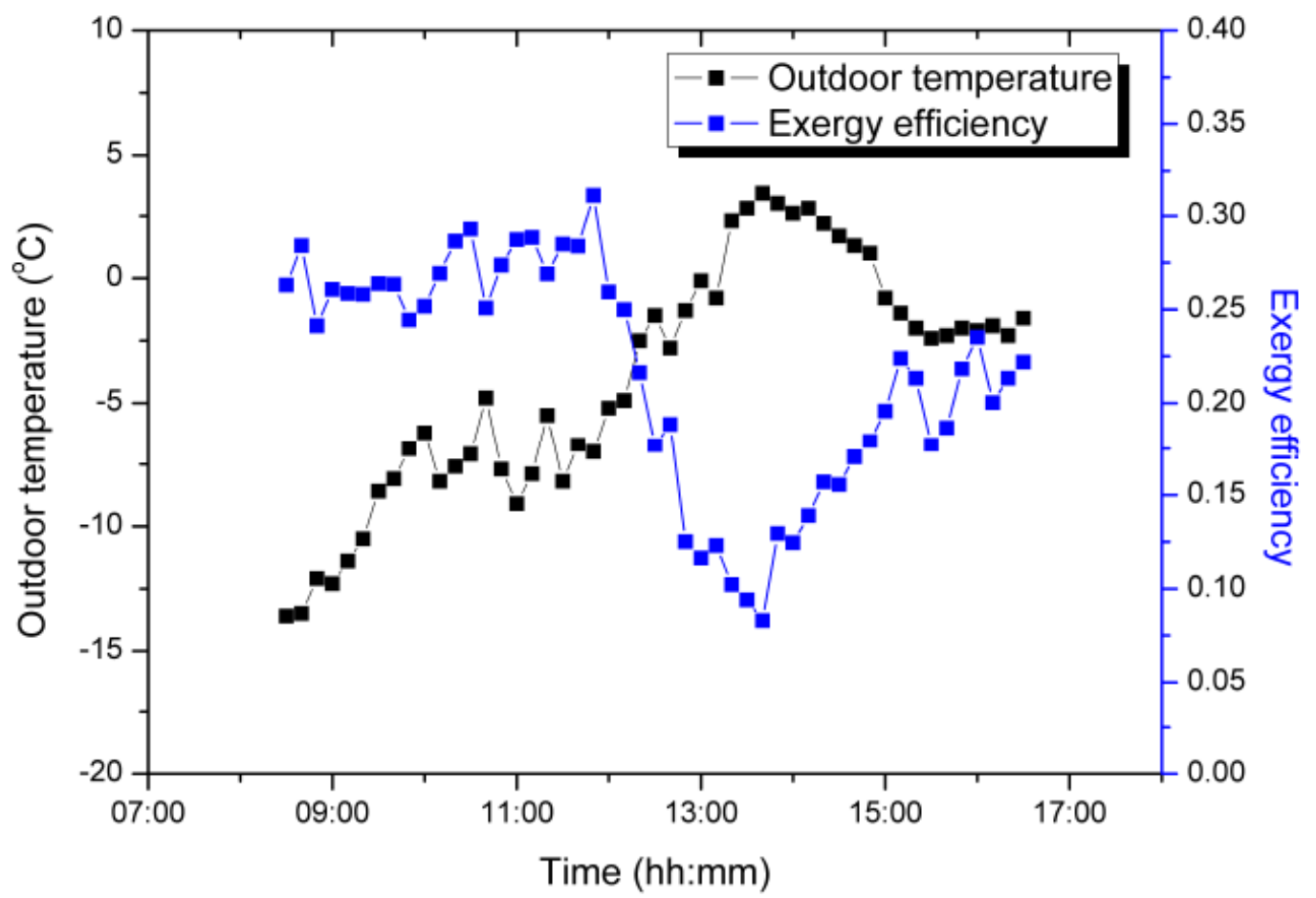

1

FIGURE 7 Outdoor temperature and exergy efficiency change with the time 


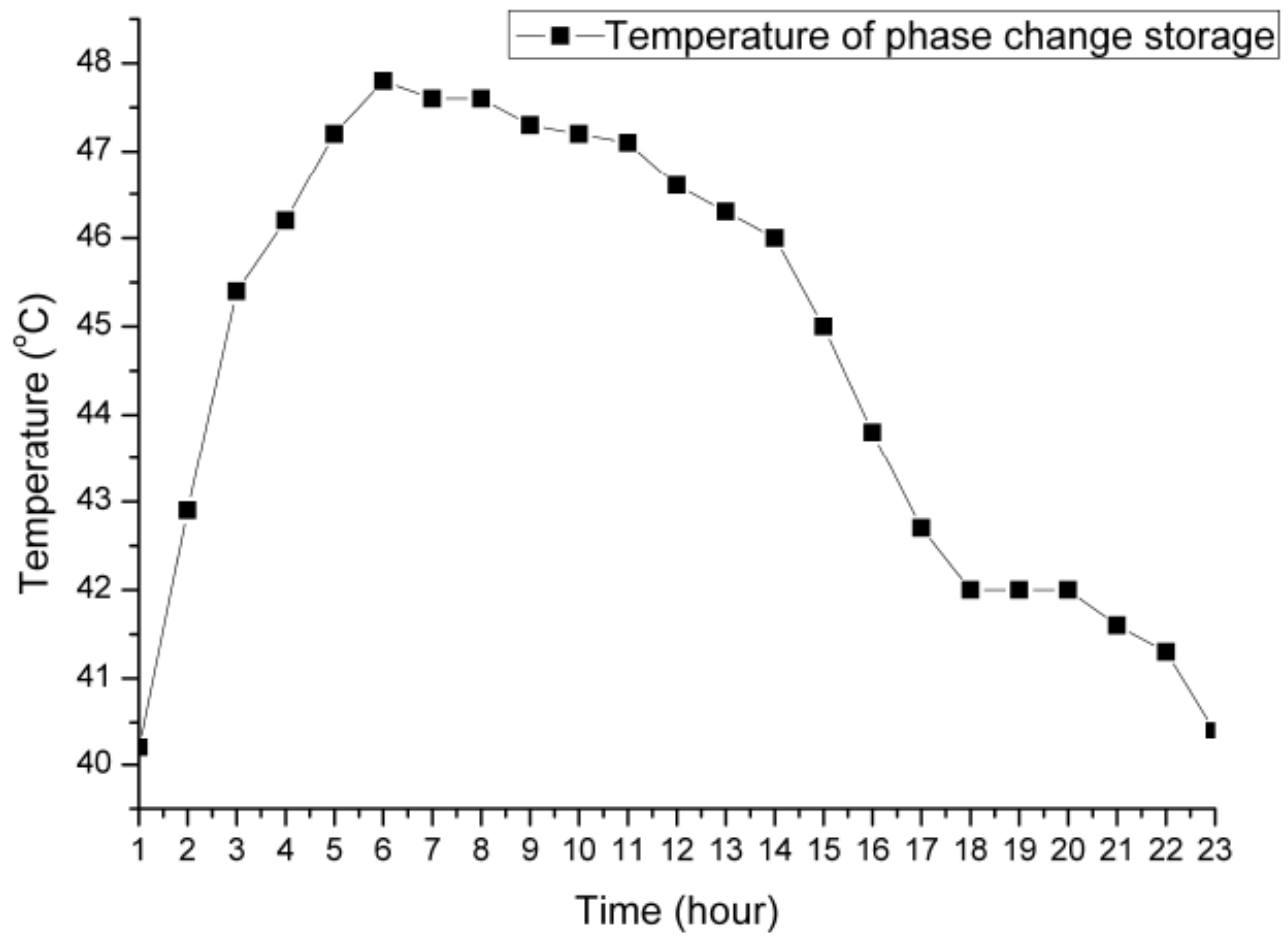

FIGURE 8 Temperature of phase change storage

2

3

4

5

6

7

8

9

10

11

12

13

14

15

16

17

18

19

20

21

22

23

24

25

26 
1 Table 1 Three defrosting methods to restore heating parameters

\begin{tabular}{ccc}
\hline Operating mode & $\begin{array}{c}\text { Air source tube-fin heat exchanger fin surface } \\
\text { temperature } /{ }^{\circ} \mathrm{C} \text { at the end of defrosting }\end{array}$ & $\begin{array}{c}\text { Restore heating } \\
\text { time } / \mathrm{s}\end{array}$ \\
\hline $\begin{array}{c}\text { Hot gas bypass } \\
\text { defrosting } \\
\text { Reverse cycle } \\
\text { defrosting } \\
\text { Energy storage } \\
\text { defrosting }\end{array}$ & 23.5 & 210 \\
\hline
\end{tabular}

2

3

4

5

6

7

8

9

10

11

12

13

14

15

16

17

18

19

20

21

22

23

24

25

26

27

28

29

30

31

32

33

34 
1 Table 2 Comparison of defrosting energy consumption and compressor input power of 2 the three defrosting modes

\begin{tabular}{cccc}
\hline Operating mode & Defrosting time / s & $\begin{array}{c}\text { Defrosting energy } \\
\text { consumption / kJ }\end{array}$ & $\begin{array}{c}\text { Compressor average input } \\
\text { power / W }\end{array}$ \\
\hline $\begin{array}{c}\text { Hot gas bypass } \\
\text { defrosting }\end{array}$ & 510 & 226.2 & 443.5 \\
$\begin{array}{c}\text { Reverse cycle } \\
\text { defrosting }\end{array}$ & 390 & 238.1 & 610.5 \\
$\begin{array}{c}\text { Energy storage } \\
\text { defrosting }\end{array}$ & 270 & 201.3 & 745.6 \\
\hline
\end{tabular}

3

4

5 